\title{
Research Production of Current Saudi Emergency Medicine Training Centers in the New Millennium: A Descriptive Study
}

\author{
Loui K. Alsulimani, SBEM, ArBem, Anas Khan'1, SBEM, MHA, and \\ Ahmed M. Bokhari², MPH, DrPH
}

Department of Emergency Medicine, Faculty of Medicine, King Abdulaziz University, Jeddah, ${ }^{1}$ Emergency Department, College of Medicine, Medical City, King Saud University, Riyadh, and '2Department of Dental Public Health, Jazan University, Jizan, Saudi Arabia

\section{Correspondence}

Dr. Loui K. Alsulimani

P.O. Box 80215, Jeddah 21589, Saudi Arabia

e.M: Ikalsulimani@kau.edu.sa

Submission: 06 Aug. 2016

Accepted: 25 Sept. 2016

\section{Citation}

Alsulimani LK, Khan A., Bokhari AM. Research production of current Saudi emergency medicine training centers in the new millennium: A descriptive study. JKAU Med Sci 2016; 23 (4): 1-10. DOI: 10.4197/Med. 23.4.1

\begin{abstract}
The development of the specialty of emergency medicine demands a concurrent development of research in the field; training emergency departments are expected to take the lead in research production. This study aims to evaluate the research production of 14 Saudi Emergency Medicine training departments, from January 2000 to June 2016. From April to July 2016, we searched for articles published by first authors affiliated with Saudi Emergency Medicine training centers. We searched for original articles using the following search engines: PubMed, Web of Science, Embase, Ovid, Scopus, Inspec, Agency for Healthcare Research and Quality, and Cochrane Central Registers. Based on previous literature, we used certain metrics to evaluate the articles: journal's impact factor, number of citations by Web of Science, number of citations by Google Scholar, and Altmetric score. Out of 9520 publications screened, only 76 articles were included for evaluation. The average number of publications per year was 4.7. However, it increased from two publications in year 2000 to 14 publications in 2015. Most of the publications ( $n=65,86 \%$ ) were in journals with no or low IF (IF < 2). Although, there is progressive improvement in the quantity and quality of research from Saudi Emergency Medicine training departments, there should be more effort to reach to a higher level of research production.
\end{abstract}

\section{Keywords}

Emergency medicine; Training departments; Research

production; Metrics

\section{Introduction}

E mergency medicine (EM) is a relatively new and rapidly growing specialty; this growth is associated with an increasing demand for research and evidence based knowledge ${ }^{[1,2]}$. As research production is linked to the development of healthcare services ${ }^{[3]}$, the growth of EM specialty was accompanied by an increase in research production ${ }^{[4]}$. Therefore, there are efforts worldwide to give a special attention for scholarly scientific work produced by emergency medicine professionals $s^{[5,6]}$. More information about the 
research status is required to guide the efforts aiming for the specialty to catch up with the older branches of medicine in the area of research and evidence based medicine $e^{[4]}$.

In 2000, the initiation for standard training in Saudi Arabia was started ${ }^{[7]}$. By the year 2016, the number of active training centers increased to 14 centers which represent all healthcare sectors in the Kingdom ${ }^{[8]}$; most of those 14 centers have a pediatric division. A study done on 4,744 US academic emergency physicians had shown that research productivity is linked to future academic progress ${ }^{[9]}$. Saudi Commission of Health Specialties encourages centers applying for accreditation to have designated research departments that promote research ${ }^{[10]}$.

There is no universally agreed on, single tool that can alone assess research productivity. Common metrics to evaluate research articles include: Number of publications, Web of Science (WOS) number of citations and Journal Impact Factor (JIF). Besides, there are new metrics, like Google Scholar citation and Altmetric score, gaining popularity with time ${ }^{[11,12]}$. Departments' research production is usually presented by the production of their staff. Although there is a variability between EM training centers in the time of recognition by SCFHS, the experience with research and the research capabilities, we aim for a crosssectional data to represent the current status of the research production as a baseline information for future development.

This study can aid in the development of research curriculum of the Saudi EM training program. We aim by our study to describe the research produced by authors officially affiliated with the leading Saudi EDs using common research metrics. Having an objectively described baseline knowledge about the research produced by Saudi EDs should be beneficial for professionals and stakeholders aiming to contribute to the research development in the field.

\section{Methods}

This study is a retrospective review of research production of Saudi EM training centers, from January 2000 to June 2016. Our study was conducted in the period from April to July 2016. We searched for articles using the following search engines: PubMed, Web of Science (WOS), Embase, Ovid, Scopus, Inspec, Agency for Healthcare Research and Quality (AHRQ), and
Cochrane Central Registers. We searched using the key phrases "Emergency" and "Saudi Arabia," utilizing "AND" as the Boolean operator. Since first authors usually contribute to most of the work ${ }^{[13,14]}$, we only included departments with first authors' affiliations documented in the articles. We included only authors who had mentioned their affiliation with any of the current active residency training ED in Saudi Arabia ${ }^{[15]}$. These inclusion criteria yielded 112 publications. A list of the 14 training EDs approved by SCFHS-which is the main accrediting body for training institutions in the Kingdom- was obtained ${ }^{[8]}$. After excluding departments not on this list, 94 publications remained.

Looking for original studies only, we excluded: editorials, reports, commentaries, review articles, book chapters, letters to the editors, animal studies, cadaveric studies and studies with topics not related to $\mathrm{EM}^{[3,4,15]}$. Thus, we ended with 76 original articles for analysis. All the metrics we used here to evaluate research production were previously used in the literature ${ }^{[16,17]}$. For all papers, we did a manual retrieval of the following variables: publication year, author's name, hospital's name, hospital type (academic or non-academic), study population (adults or pediatrics), journal's access (open or restricted) and number of authors. Studies were classified as: retrospective studies, case reports/series, cross sectional, prospective studies, meta-analyses, and controlled trials. Data about co-authors' locations, multi-centricity and specialties were retrieved to assess collaboration ${ }^{[16]}$.

A list of authors' genders, main credentials and population of clinical practice (adults or pediatrics) was created to collect data about these variables. Thompson Reuters 2015 Edition Journal Citation Report (JCR) database was used to retrieve journals' Impact Factor (IF), location and specialty. We used the JCR's list of EM journals, to classify journals into EM and non-EM. If the journal was not on the list, we had to decide about the classification based on the journal's title and its website introduction. If the journal's location was not in JCR database, it was retrieved from its website. The topics of the articles were classified based on a list of EM topics previously mentioned in literature ${ }^{[11,18]}$. We got the number of articles' citations from ISI Web of Science database.

Also, we collected another metric of increasing popularity among scholars, which is Google Scholar number of citations ${ }^{[18]}$. Altmetric score is another new metric considering the scholarly use of social media, 
which has been described in previous researches ${ }^{[12,19]}$. To get this score, we used the Altmetric bookmarklet for Mozilla Firefox Internet browser (available at www. altmetric.com, Altmetric LLP, London, UK). On July 31 from 1:00 to 16:00 we did a final review of our search to ensure retrieving the most updated data about included articles, number of citations and Altmetric scores.

We utilized the collected data to generate information about the following: (1) The progress of research production over the years; (2) Difference of production between Saudi board-certified physicians and others with different certifications; (3) First author nationality; (4) Distribution of publications among EM topics. The sources for information about the board certification were direct contact, colleagues, personal web pages and institutional websites. We further described the publications of the top four publishing departments, publishing journals, and frequently publishing researchers. In our methodology, authorship centricity was categorized either as a single center (including studies with a single author) or multi-centred (including studies with international co-authors). For the year 2016, because of the research conduction time, we were limited by the ability to include only half of the year (up to the end of June). This study received approval from the Institutional Review Board (IRB) of King Saud University College of Medicine on 3/3/2016 (Ref.No.16/0101/IRB).

\section{Statistical Analysis}

All the statistical analyses were utilized by statistical software package for social sciences SPSS 24.0 (IBM Corp., Released 2016. IBM SPSS Statistics for IOS Macintosh, Version 24.0. Armonk, NY USA). For generating frequencies, percentages, means and standard deviations for demographic data, descriptive statistics were executed. To test for the assumptions for normality of the data, Shaphiro-Wilk test was used to test for normality and Levene's test for homogeneity of variance. Regarding categorical variables, chi-square test was used to compare between the proportions. The significant differences between the values were obtained via 95\% confidence intervals. KruskalWallis test was used to compare between medians of board training group with various publication tools and scores. The $p$-value of less than 0.05 was used to confirm statistically significant differences. The $p$-value of $<0.05$ was used to detect the statistically significant linear relationship between variables.

\section{Results}

Number of publications per year has shown a progressive increase, with year 2015 showing the highest number of publications $(n=14)$, (Fig. 1). However, in the first half of the year 2016 there were eight publications; with a high chance of this year to be the highest in the number of publications. A drop of the

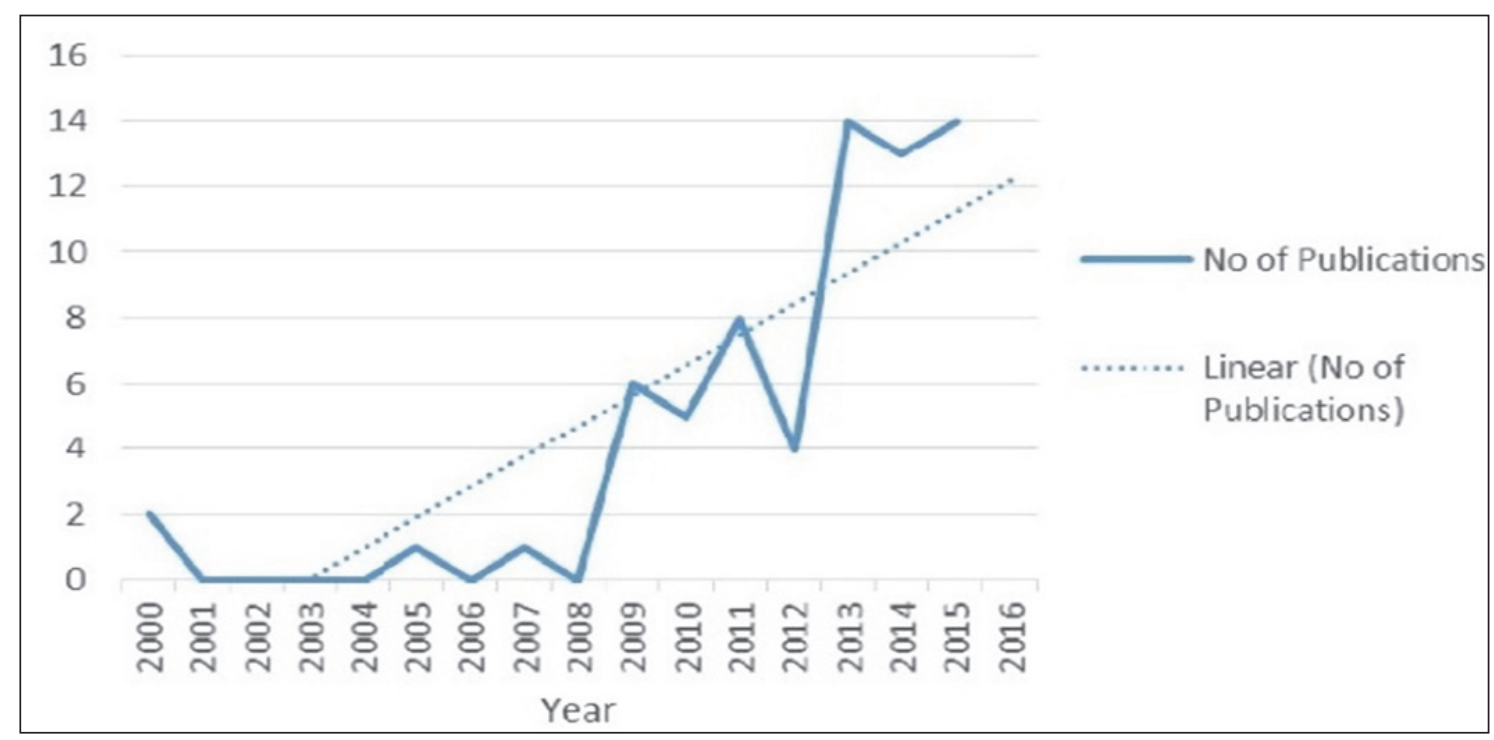

Figure 1. Number of publications over the years. 
number of publications was observed at year $2012(n=$ 4); the reason for this drop was not clear. Characteristics of the 76 publications included in our study was represented by (Table 1). Among the 14 training EDs, university affiliated hospitals took the upper hand in the number of publications. It was noticed that most of the publications came from departments located in the central region of the Kingdom (specifically Riyadh, the capital). It was striking that four EDs out of the 14 did not produce any research in our study period. Also, five EDs produced only 1 article during this relatively long period. In Table 2, a more detailed description was given about research production of the top 4 research producing EDs. Publications coming from adult sections ( $n=42,55.3 \%$ ) were more frequent than publications from pediatric sections.

The 76 publications were the production of 40 first authors affiliated with Saudi training EDs. The research production of male $(n=33,82.5 \%)$ investigators were significantly higher than their female counterparts. Researchers with Saudi nationality produced most of the publications ( $n=63,82.9 \%)$. First authors with Saudi Board certification were more predominant in number of publications in comparison to those with North American and other types of certifications (Table 3).

Interestingly, almost half of the publications were in EM specialized journals, while the remaining publications were divided between general and nonEM specialized journals. Most of the 76 publications were in North American journals. Exactly, half of the publications were in open access journals. Pediatric Emergency Care journal was the most frequent publishing journal $(n=6,8 \%)$ followed by Journal of Emergencies, Trauma and Shock $(n=4,5 \%)$. Interestingly, only $13(17.1 \%)$ articles were published in Saudi journals; most commonly in the Saudi Journal of Kidney Diseases and Transplantation ( $n=4,30 \%)$. The overall mean IF for journals included in our study was 1.65. There were 33 articles (43.4\%) published in journals not indexed by the ISI Thompson Reuters; which made the retrieval of journals'IF, as well as WOS citation numbers, impossible. In Table 4 there is a description about the top articles ranked according to the journals' IFs.

Toxicology topics were the most frequent among the 76 articles' topics ( $n=12,15.8 \%$ ), followed by administration topics ( $n=8,10.5 \%$ ) (Fig. 2). The most
Table 1. Descriptive statistics for demographic data of publishers.

\begin{tabular}{|c|c|c|}
\hline Number of Primary Authors & $\mathrm{N}=40$ & Percentage $(\%)^{\dagger}$ \\
\hline \multicolumn{3}{|l|}{ Gender } \\
\hline Males* & 34 & $85 \%$ \\
\hline Females & 6 & $15 \%$ \\
\hline Number of Publications & \multicolumn{2}{|c|}{$N=76$} \\
\hline \multicolumn{3}{|l|}{ Board Certification } \\
\hline Saudi Board & 37 & $48.68 \%$ \\
\hline Canadian Board & 16 & $21.05 \%$ \\
\hline American Board & 11 & $14.47 \%$ \\
\hline Others & 12 & $15.79 \%$ \\
\hline \multicolumn{3}{|l|}{ Hospital Type } \\
\hline Academic & 71 & $93.42 \%$ \\
\hline Non-Academic & 5 & $6.57 \%$ \\
\hline \multicolumn{3}{|l|}{ Region } \\
\hline Central & 70 & $92.11 \%$ \\
\hline Western & 5 & $6.57 \%$ \\
\hline Eastern & 1 & $1.31 \%$ \\
\hline \multicolumn{3}{|l|}{ Type of Study } \\
\hline Retrospective & 20 & $26.31 \%$ \\
\hline Case Report/Series & 21 & $27.63 \%$ \\
\hline Cross Sectional & 22 & $28.89 \%$ \\
\hline Prospective & 8 & $10.53 \%$ \\
\hline Systematic Review & 0 & 0 \\
\hline Randomized Trial & 3 & $3.95 \%$ \\
\hline Meta-analysis & 2 & $2.63 \%$ \\
\hline Literature Review & 0 & 0 \\
\hline \multicolumn{3}{|l|}{ Population of the Study } \\
\hline Adult & 41 & $53.95 \%$ \\
\hline Pediatric & 34 & $44.74 \%$ \\
\hline Both & 1 & $1.31 \%$ \\
\hline \multicolumn{3}{|l|}{ Journal Specialty } \\
\hline Emergency & 28 & $36.84 \%$ \\
\hline Other Specialty & 26 & $34.21 \%$ \\
\hline General & 22 & $28.95 \%$ \\
\hline \multicolumn{3}{|l|}{ Journal Location } \\
\hline Local & 15 & $19.74 \%$ \\
\hline North America & 38 & $50.00 \%$ \\
\hline Asia & 12 & $15.78 \%$ \\
\hline Europe & 11 & $14.47 \%$ \\
\hline \multicolumn{3}{|l|}{ Countries of Contributing Co-authors } \\
\hline Saudi Arabia (Local) & 49 & $60.49 \%^{\dagger}$ \\
\hline Canada & 14 & $17.28 \%$ \\
\hline USA & 8 & $9.88 \%$ \\
\hline UK & 5 & $6.17 \%$ \\
\hline Pakistan & 2 & $1.24 \%$ \\
\hline India & 1 & $1.24 \%$ \\
\hline Lebanon & 1 & $1.24 \%$ \\
\hline Australia & 1 & $1.24 \%$ \\
\hline \multicolumn{3}{|l|}{ Access } \\
\hline Open & 38 & $50 \%$ \\
\hline Close & 38 & $50 \%$ \\
\hline \multicolumn{3}{|l|}{ Center Type for Co-authors } \\
\hline Single Center & 43 & $56.58 \%$ \\
\hline Multiple Centers & 33 & $43.42 \%$ \\
\hline
\end{tabular}


Research Production of Current Saudi Emergency Medicine Training Centers in the New Millennium: A Descriptive Study L.K. Alsulimani et al.

Table 2. Descriptive and mean comparisons statistics of journals rank and articles citations tool according to Co-authors' affiliated hospitals.

\begin{tabular}{|c|c|c|c|c|c|c|}
\hline Hospital & $\begin{array}{c}\text { No. of } \\
\text { Publications }\end{array}$ & Impact Factor & Altmetric Score & WOS Citations & $\begin{array}{l}\text { Google Scholar } \\
\text { Citations }\end{array}$ & $\begin{array}{c}\text { Primary } \\
\text { Investigators }\end{array}$ \\
\hline $\begin{array}{l}\text { King Khalid University } \\
\text { Hospital-Riyadh }\end{array}$ & 26 & 15 & 13 & 9 & 15 & 14 \\
\hline $\begin{array}{l}\text { National Guard Hospital- } \\
\text { Riyadh }\end{array}$ & 29 & 15 & 15 & 5 & 15 & 13 \\
\hline $\begin{array}{l}\text { King Faisal Specialist } \\
\text { Hospital-Riyadh }\end{array}$ & 9 & 3 & 2 & 2 & 4 & 3 \\
\hline $\begin{array}{l}\text { King Fahad Medical City- } \\
\text { Riyadh }\end{array}$ & 4 & 1 & 2 & 1 & 2 & 3 \\
\hline Other Hospitals & 8 & 4 & 5 & 4 & 2 & 7 \\
\hline Overall & 76 & $1.11(0.87,2.03)^{* \dagger}$ & $0(0,3)^{\dagger}$ & $1(0,0.75)^{\dagger}$ & $1(0,7)^{\dagger}$ & 40 \\
\hline
\end{tabular}

Abbr.: WOS: Web of Science: "P value $<0.05$ of one-way Kruskal-Wallis test." ${ }^{\text {"t }}$ Median and $\left(25^{\text {th }}, 75^{\text {th }}\right)$ interquartile range

Table 3. Comparing research production according to board certification.

\begin{tabular}{|l|c|c|c|c|c|c|}
\hline & Saudi Board & Canadian Board & American Board & Others & Range & P-Value \\
\hline No. of Publications & 18 & 9 & 6 & 5 & $(1-76)$ & 0.837 \\
\hline No. of WOS Citations & 9 & 4 & 3 & 3 & $(0-61)$ & 0.993 \\
\hline No. of Google Scholar Citations & 22 & 8 & 5 & 5 & $(0-18)$ & 0.673 \\
\hline Journals' Impact Factors & 8 & 5 & 6 & 2 & $(0-7)$ & 0.323 \\
\hline Altmetric Score & 15 & 7 & 5 & 10 & $(0-36)$ & 0.157 \\
\hline
\end{tabular}

Abbr.: WOS: Web of Science; Median (range). ${ }^{*} P<0.05$ Kruskal-Wallis test

Table 4. Top five published articles according to the journal's impact factor.

\begin{tabular}{|l|l|c|c|c|c|}
\hline \multicolumn{1}{|c|}{ Article } & \multicolumn{1}{c|}{ Journal } & Impact Factor & Google Scholar Citations & WOS Citations & Altmetric Score \\
\hline Alsolamyy & Critical Care Medicine & 7.42 & 8 & 6 & 10 \\
\hline Altamimi et al. ${ }^{[36]}$ & The Cochrane Collaboration & 6.04 & 23 & 5 & 10 \\
\hline Abualenain et al. ${ }^{[2]}$ & Annals of Emergency Medicine & 5.01 & 19 & 18 & 36 \\
\hline Salleeh et al. ${ }^{[3]}$ & The Journal of Pediatrics & 3.89 & 2 & 1 & 0 \\
\hline${\text { Alhelail et al. }{ }^{[38]}}$ & Clinical Toxicology & 2.89 & 9 & 2 & 10 \\
\hline
\end{tabular}

Abbr.: WOS: Web of Science

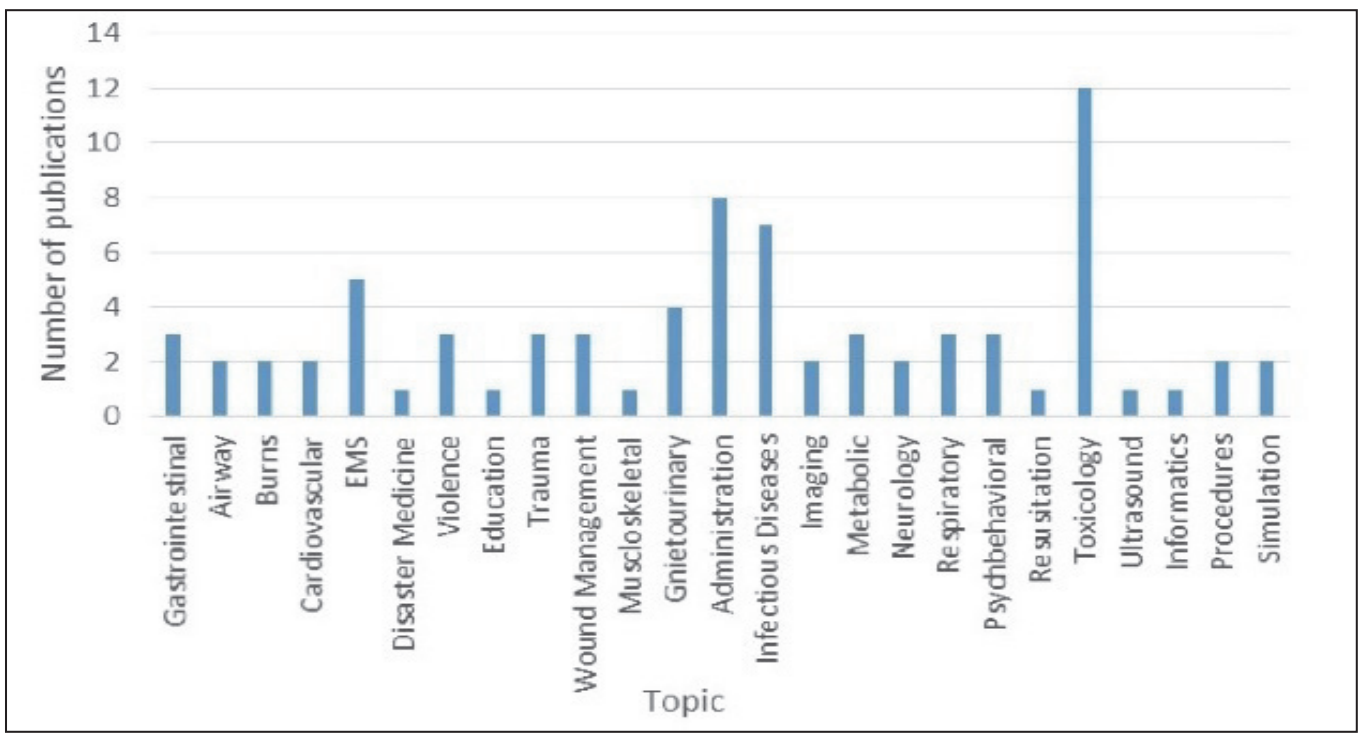

Figure 2. Topics distribution of the publications. 
frequent type of studies was distributed almost equally between retrospective, case report/series and crosssectional studies. For all the publications, the mean number of WOS number of citations was 3.53; this number was correlated to the mean number of citations by Google scholar for all studies included, which was $4.83\left(R^{2}=0.65\right.$, P-value $\left.<0.0001\right)$. This correlation finding ascertained the similar correlation found before in previous studies ${ }^{[20,21]}$. Regarding Altmetric scores, the overall mean was 2.75 . The highest article's WOS citation number was 18 , and the highest Altmetric score was 36; both were for the study of Abualenain et al. ${ }^{[22]}$ Whereas the highest article's Google Scholar number of citations was 61 for Al Eissa et al. ${ }^{[23]}$

The overall mean number of authors per article was 4.8; there were only 7 studies with single author. Co-authors were either from Saudi Arabia (Local), outside Saudi Arabia, or both. Articles with only local co-authors were more common $(n=49,64.5 \%)$, and they were often from the same institution $(n=43$, $87.8 \%$ ). There were 27 publications with co-authors from outside Saudi Arabia; co-authors were from Canada ( $n=14,51.9 \%)$, US $(n=8,29.6 \%)$, UK $(n=5$, $18.5 \%)$, Australia ( $n=1,3.7 \%$ ) and other Asian countries $(n=4,14.8 \%)$. Nevertheless, co-authors from other specialties contributed to 34 studies (44.7\%); half of those studies had co-authors from the department of pediatrics. Other departments such as Biostatistics $(n=$ $4,11.8 \%)$, Family \& Community Medicine $(n=4,11.8 \%)$, Nursing ( $n=3,8.8 \%)$, Child Abuse and Neglect $(n=3$, $8.8 \%)$, Intensive Care $(n=2,5.9 \%)$, Epidemiology $(n=2$, $5.9 \%)$ and Quality Management $(n=2,5.9 \%)$ had less contribution.

\section{Discussion}

Our study showed an obvious increase of number of publications from 2 studies in year 2000 to 14 studies in year 2015. However, a total number of 76 articles over 16 years is obviously very low. The research status of other specialties such as nephrology, gastroenterology, and orthopedics in Saudi Arabia has been described in literature ${ }^{[24-26]}$; the conclusion reflects a deficiency in research production in Saudi Arabia.

The medical research production from Saudi Arabia in general was addressed by many authors before. Latif ${ }^{[27]}$ found a linear progress in the number and quality of publications coming from Saudi Arabia in the period from 2008-2012. A similar conclusion was described by Al-Bishri[28], who compared the production of Saudi Arabia with other countries where Saudi Arabia ranked $16^{\text {th }}$ internationally in number of publications after some countries in the same region with lower population and incomes like Lebanon, Kuwait and United Arab Emirates; with 72.7 articles per million population. He addressed some of the causes of these findings including lack of: funds, research skills and academic recognition. Another study by Aziz et al. ${ }^{[29]}$ gave a more explicit explanation of the causes of research underproduction, especially from academic centers.

Regarding EM, Wilson and Itagaki ${ }^{[4]}$ described the international contribution from all over the world in EM scholar research production; Saudi Arabia was not from the first 20 contributing countries. United States comes first worldwide in regard to EM research production ${ }^{[14,30]}$.To our knowledge, there is no published study that describes the research productivity of Saudi emergency departments.

We believe that the Saudi EDs, which got the credentials from SCHS to be training centers, should be leading the EM research in the Kingdom for many reasons. First, they have abundant resources like libraries, research centers, and research funding chairs (grants). Second, larger centers have qualified personnel with experience in research, including physicians, biostatisticians, and research assistants. Third, academic centers should have the motivation for high research productivity for promotion purposes. Finally, the training environment with professional senior physicians and enthusiastic junior medical staff should be ideal for the growth of research production.

A significant percentage of the departments, $64 \%$ (9 out of 14) produced only one article or nothing in this long period; this could be of a serious concern. The specific reasons for such a significant finding has not been studied, however, the general reasons of insufficient research in Saudi Arabia could apply. These reasons include lack of: incentives, funds, research skills, academic recognition, and a research promoting system (1).

Due to the absence of statistics or national registry about Saudi EM physicians, it was difficult to compare the demographics found here with the national numbers (Table 1). For example, Saudi female EM physicians had a lower production than their counterpart males in number of publications; it is not clear if this is secondary to their lower presence in 
EDs or due to a lower productivity; this can be an area for future study. However, an international study had shown a lower production of female EM physicians ${ }^{[3]}$. Although Saudi board-certified physicians had the upper hand in number of publications, physicians with American board produced higher quality research (Table 2).

The division of publications between EM journals and non-EM journals was equal. Wilson and Itagaki ${ }^{[4]}$, showed in their study the direction toward non-EM journals; another study showed an opposite trend towards publication in EM-journals ${ }^{[32]}$. The number of publications per year (mean 4.75) is still not sufficient to establish a designated Saudi journal for EM depending on local production. Having half of the publications in open access journals is going with the intention of EM investigators towards open access journals ${ }^{[33]}$. The low percentages of research published in Saudi journals (17.1\%) should draw the attention of the editors of those journals to attract local EM authors. The trend of publishing in low IF journals (IF $<2)^{[14]}$ discovered in this study is similar to the national trend ${ }^{[27]}$. The mean journal IF of publications found in our study was 0.993; whereas the EM publications from US has an IF of $1.77^{[4]}$. Saudi EM researchers should be promoted to target prestigious journals with high IFs.

From Figure 2, future researchers can have an idea about EM topics not covered by local researchers, and topics of the most interest. Clinical toxicology was targeted in local research more than other subspecialties in $\mathrm{EM}$; this trend was similarly found in an international study ${ }^{[32]}$. However, another study found that trauma topics were the most prevalent ${ }^{[3]}$. Research types at the bottom of the evidence-based pyramid (i.e., retrospective studies, case reports/series, and crosssectional studies) were predominant. The mean WOS and Google citations were 1.67 and 4.83, respectively. Li et al. ${ }^{[14]}$ presented in their study the mean numbers of WOS citations for different countries; for example: USA 4.89, UK 5.27, and Canada 5.83. The mean Altmetric score in our study, was found to be 2.4, interestingly, higher than a mean of 1.9 which was found in an international study ${ }^{[12]}$. This could be explained by the absence of Altmetric scoring for many of the included studies, since many of the studies got published in lower quality journals, with no documented scores. So, the proportion of studies with documented Altmetric scores (the stronger studies) will be falsely higher, and will falsely raise the overall mean score. Whereas in US publications, most of the studies (strong or weak) were published in journals with documented scores, which dilutes the overall mean score. Another possibility is the popularity of social media (Twitter and Facebook) in Saudi Arabia ${ }^{[34]}$.

It has been noticed that in 13 articles (17.1\%), the first authors were affiliated with institutions outside Saudi Arabia in addition to their Saudi affiliations. Mostly, those could be publications done during their scholarships outside the Kingdom. Most of the Saudi EM board certified physicians get to do one or two years of sub-specialty fellowship. Further studies can be done to assess the effect of these scholarships on the quantity and quality of research production. Another concerning finding is that almost all the publications were by physicians who already finished their board training; only one study done by a nurse and another two studies by residents. Residents should be trained and supported to do research, as they can be important assets in improving the research productivity of Saudi Arabia. The percentages of multicenter studies (43\%) was higher than that found in a previously published international article $(27.9 \%)^{[3]}$. Co-authorship is a surrogate marker for coordination and collaboration in research ${ }^{[28]}$. The multiplicity of co-authors, distribution of their countries and the diversity of their specialties all are signaling the presence of foundational level of collaboration in research.

A common limitation in this study (and similar studies) is the inclusion of first authors' studies only; it was difficult to find a method to assure the credit of the work is legitimately related to the EDs. Future studies may look at the contribution of middle and last authors. Also, due to the lack of official data about the year of credentialing by SCFHS for each ED, it was difficult to adjust the findings according to the approval year for each center. Although the inclusion of studies from 2015 and 2016 had limitations in reflecting the research metrics, they added valuable information to our knowledge about the publications. The presence of different methodologies in international studies limited the ability to compare our findings, statistically, with their findings. Nevertheless, the findings in this study were described in relation with international literature.

This research can establish the ground for future work intending to improve EM research in Saudi Arabia. Collaborative efforts, with the lead of training EDs, should be directed to promote research production. There should be an investment in research training, 
staff incentives, infrastructure development, research centers activation and international collaboration. The improvement of research status should eventually translate into a better quality of care in Saudi EDs; which will reflect on the quality of care in the Kingdom.

The idea of measuring research productivity is intriguing but complex because of multiple domains and variables. It would seem intuitive, however, that as the number of residency programs, residents, and staff increase with time, so will academic productivity. As part of that academia, original research publications might be also expected to occur. However, the skills and resources required to produce publishable original research are not common and can takes years to develop. Without appropriate research training and mentorship programs and skilled and enthusiastic individuals who are willing to pursue research, the number of original research publications from any given program are likely to be very limited. To that end, judgment about a subjective perception of lack of productivity is unfair. Just as it has taken many years to development a Saudi Arabian emergency medicine residency training program to provide the Kingdom with skilled emergency physicians, it will also take many years to develop Saudi Arabian emergency medicine research training programs. Currently, there is no special research training for EM residents, nor are there a pre-set expected level of research productivity. We hope this research paper will be a starting point for improving research production from the leading EDs in the Kingdom.

\section{Conflict of Interest}

The authors have no conflict of interest.

\section{Disclosure}

The authors did not receive any type of commercial support either in forms of compensation or financial for this study. The author have no financial interest in any of the products or devices, or drugs mentioned in this article.

\section{Ethical Approval}

Obtained.

\section{References}

[1] Perry JJ, Snider CE, Artz JD, Stiell IG, Shaeri S, McLeod S, Le Sage N, Hohl C, Calder LA, Vaillancourt C, Holroyd B, Hollander JE, Morrison LJ. CAEP 2014 Academic
Symposium: "How to make research succeed in your emergency department: How to develop and train career researchers in emergency medicine". CJEM 2015; 17(3): 334-343.

[2] Lee $\mathrm{CH}$, Shih $\mathrm{CP}$, Chang YC, Chaou CH. The evolution of academic performance in emergency medicine journals: viewpoint from 2000 to 2009 journal citation reports. Acad Emerg Med 2011; 18(8): 898-904.

[3] Bounes V, Dehours E, Houze-Cerfon V, Vallé B, Lipton R, Ducassé JL. Quality of publications in emergency medicine. Am J Emerg Med 2012; 31(2): 297-301.

[4] Wilson MP, Itagaki MW. Characteristics and trends of published emergency medicine research. Acad Emerg Med 2007; 14(7): 635-640.

[5] Stiell IG, Artz JD, Perry J, Vaillancourt C, Calder L. Executive summary of the CAEP 2014 Academic Symposium: How to make research succeed in your department. CJEM 2015; 17(3): 328-333.

[6] Koroshetz WJ; NIH Task Force on Research in Emergency Setting. $\mathrm{NIH}$ and research in the emergency setting: progress, promise, and process. Ann Emerg Med 2010; 56(5): 565-567.

[7] Qureshi N. International perspective from Saudi Arabia on "Procedural Skills Training during Emergency Medicine Residency: Are we teaching the right things?". West J Emerg Med 2009; 10(3): 157-158.

[8] [No authors listed]. Recognized Centers. Saudi Commission for Health Specialties (SCFHS). Accessed on June 20, 2017. <http://www.scfhs.org.sa/en/MESPS/ TrainingProgs/TrainingProgsStatement/Emergency/ Pages/RecognizedCenters.aspx>.

[9] DeLuca LA Jr, St John A, Stolz U, Matheson L, Simpson A, Denninghoff KR. The distribution of the h-index among academic emergency physicians in the United States. Acad Emerg Med 2013; 20(10): 997-1003.

[10] [No authors listed]. Accreditation Requirements and Process. Saudi Commission for Health Specialties (SCFHS). Accessed on June 20, 2017. <http://www.scfhs.org.sa/en/ MESPS/TCRecognition/TCRecProcedures/Pages/default. aspx>.

[11] Cabezas-Clavijo A, Delgado-López-Cózar E. [Google Scholar and the h-index in biomedicine: The popularization of bibliometric assessment]. Med Intensiva 2013; 37(5): 343-354.

[12] Barbic D, Tubman M, Lam H, Barbic S. An analysis of altmetrics in emergency medicine. Acad Emerg Med 2016; 23(3): 251-268.

[13] Cui H, Gao QQ, Gao LL. Scientific publication in emergency medicine from mainland China, Hong Kong, and Taiwan: a 10-year survey of the literature. Am J Emerg Med 2013; 31(5): 881-883.

[14] Li Q, Jiang Y, Zhang M. National representation in the emergency medicine literature: a bibliometric analysis of 
highly cited journals. Am J Emerg Med 2012; 30(8): 15301534.

[15] Schlenker MB, Manalo E, Wong AM. Research productivity of Canadian ophthalmology departments in top 10 ophthalmology and vision science journals from 2001 to 2010. Can J Ophthalmol 2013; 48(1): 46-55.

[16] Carpenter CR, Cone DC, Sarli CC. Using publication metrics to highlight academic productivity and research impact. Acad Emerg Med 2014; 21(10): 1160-1172.

[17] Lim KJ, Yoon DY, Yun EJ, Seo YL, Baek S, Gu DH, Yoon SJ, Han A, Ku YJ, Kim SS. Characteristics and trends of radiology research: a survey of original articles published in AJR and Radiology between 2001 and 2010. Radiology 2012; 264(3): 796-802.

[18] Waseem M, Uffer H, Josephson E. An Audit of Top Citations Published in Pediatric Emergency Care. Pediatr Emerg Care 2016; 32(5): 279-285.

[19] Liu CL, Xu YQ, Wu H, Chen SS, Guo JJ. Correlation and interaction visualization of altmetric indicators extracted from scholarly social network activities: dimensions and structure. J Med Internet Res 2013; 15(11): e259.

[20] Kulkarni AV, Aziz B, Shams I, Busse JW. Comparisons of citations in Web of Science, Scopus, and Google Scholar for articles published in general medical journals. JAMA 2009; 302(10): 1092-1096.

[21] Minasny B, Hartemink AE, McBratney A, Jang HJ. Citations and the $h$ index of soil researchers and journals in the Web of Science, Scopus, and Google Scholar. Peer J 2013; 1: e183.

[22] Abualenain J, Frohna WJ, Shesser R, Ding R, Smith M, Pines JM. Emergency department physician-level and hospitallevel variation in admission rates. Ann Emerg Med 2013; 61(6): 638-643.

[23] Al Eissa M, Almuneef M. Child abuse and neglect in Saudi Arabia: journey of recognition to implementation of national prevention strategies. Child Abuse Negl 2010; 34(1): 28-33.

[24] Makhdom AM, Alqahtani SM, Alsheikh KA, Samargandi OA, Saran N. Level of evidence of clinical orthopedic surgery research in Saudi Arabia. Saudi Med J 2013; 34(4): 395400.

[25] Almaghrabi MM, Alamoudi AS, Radi SA, Merdad AA, Makhdoum AM, Batwa FA. Quality of gastroenterology research published in Saudi Arabian scientific journals. Saudi J Gastroenterol 2015; 21(2): 90-94.

[26] Al-Khader AA, Al-Jondeby MS, Shaheen FA. Impact of nephrology publications from Saudi Arabia in the last decade. Saudi Med J 2002; 23(10): 1177-1180.

[27] Latif R. Medical and biomedical research productivity from the Kingdom of Saudi Arabia (2008-2012). J Family Community Med 2015; 22(1): 25-30.

[28] Al-Bishri J. Evaluation of biomedical research in Saudi Arabia. Saudi Med J 2013; 34(9): 954-959.
[29] Aziz KA, Sallam T, Ibrahim AH, Sufian T. Improvement of research and biomedical publication. Saudi Med J 2004; 25(10): 1319-1322.

[30] Shuaib W, Acevedo JN, Khan MS, Santiago LJ, Gaeta TJ. The top 100 cited articles published in emergency medicine journals. Am J Emerg Med 2015; 33(8): 1066-1071.

[31] Li SF, Latib N, Kwong A, Zinzuwadia S, Cowan E. Gender trends in emergency medicine publications. Acad Emerg Med 2007; 14(12): 1194-1196.

[32] Callaham M, Weber E, Wears R. Citation characteristics of research published in Emergency Medicine versus other scientific journals. Ann Emerg Med 2001; 38(5): 513-517.

[33] Rodriguez RM, Wong J, Hardy J, Frankel E. An evaluation of emergency medicine investigators' views on open access to medical literature. Emerg Med J 2006; 23(12): 895-898.

[34] Alsobayel $H$. Use of social media for professional development by health care professionals: a crosssectional web-based survey. JMIR Med Educ 2016; 2(2): e15.

[35] Alsolamy S. Middle East respiratory syndrome: knowledge to date. Crit Care Med 2015; 43(6): 1283-1290.

[36] Altamimi S, Khalil A, Khalaiwi KA, Milner RA, Pusic MV, Al Othman MA. Short-term late-generation antibiotics versus longer term penicillin for acute streptococcal pharyngitis in children. Cochrane Database Syst Rev 2012; (8): CD004872.

[37] Bin Salleeh H, McGillivray D, Martin M, Patel H. Duration of fever affects the likelihood of a positive bag urinalysis or catheter culture in young children. J Pediatr 2010; 156(4): 629-633.

[38] Alhelail MA, Hoppe JA, Rhyee SH, Heard KJ. Clinical course of repeated supratherapeutic ingestion of acetaminophen. Clinic Toxicol (Phila) 2011; 49(2): 108-112. 


\section{الإنتاج البحثي لأقسام طب الطوارئ التدريبية الحالية في المملكة العربية

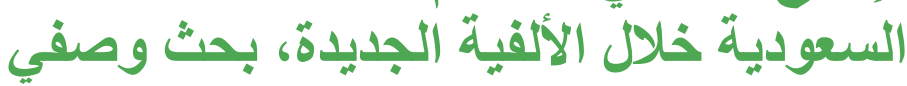

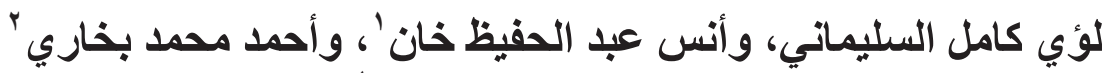

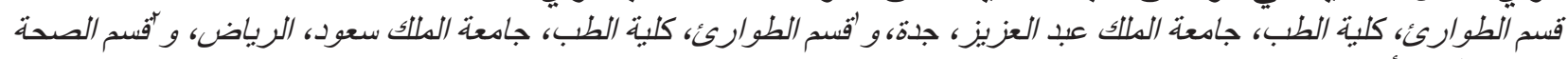

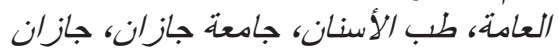

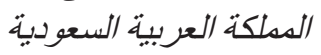

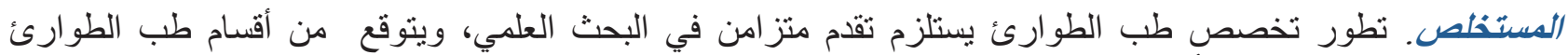

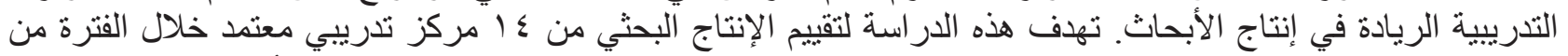

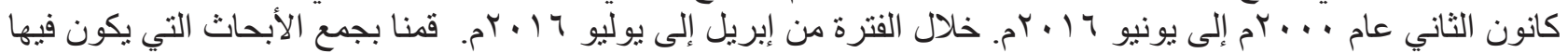

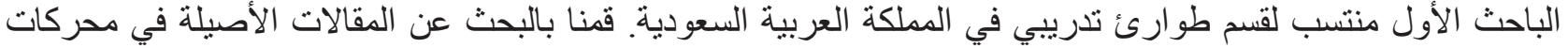

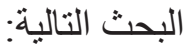

PubMed, Web of Science, Embase, Ovid, Scopus, Inspec, Agency for Healthcare Research and Quality, and Cochrane Central Registers.

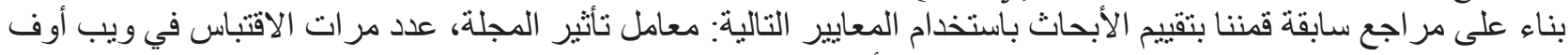

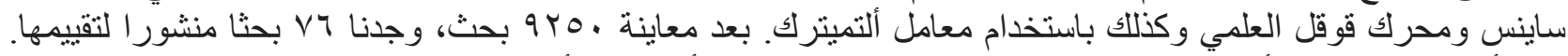

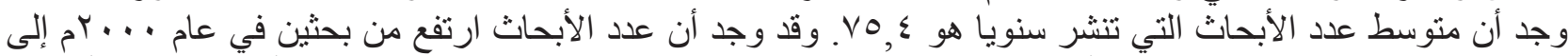

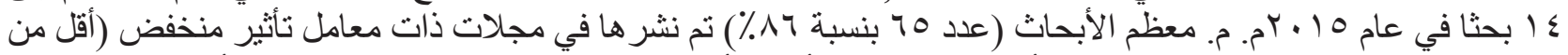

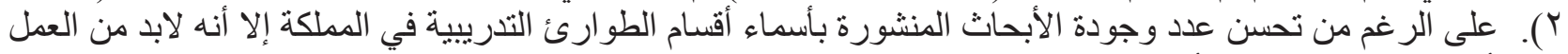
بجه أكبر للوصول لمستوى أفضل. 